\title{
Neutrophil to Lymphocyte Ratio and Mean Platelet Volume as Inflammatory Indicators in Systemic Lupus Erythematosus Nephritis
}

\author{
Ata Bora AYNA, ${ }^{1}$ Selime ERMURAT, ${ }^{2}$ Belkıs Nihan COŞKUN, ${ }^{2}$ \\ Halil HARMAN, ${ }^{3}$ Yavuz PEHLIVAN ${ }^{2}$ \\ ${ }^{1}$ Department of Physical and Rehabilitation, Division of Rheumatology, Medical Faculty of Uludağ University, Bursa, Turkey \\ ${ }^{2}$ Department of Internal Medicine, Division of Rheumatology, Medical Faculty of Uludağ University, Bursa, Turkey \\ ${ }^{3}$ Department of Physical and Rehabilitation, Division of Rheumatology, \\ Medical Faculty of Izzet Baysal Training and Research Hospital, Bolu, Turkey
}

\begin{abstract}
Objectives: This study aims to evaluate the role of neutrophil to lymphocyte ratio (NLR) and mean platelet volume (MPV) as activation and inflammatory markers in systemic lupus erythematosus (SLE) patients with nephritis.

Patients and methods: A total of 108 SLE patients ( 8 males, 100 females; mean age $35.3 \pm 10.2$ years; range 16 to 64 years) including 78 patients with renal involvement ( 8 males, 70 females; mean age 33.9 \pm 10.6 years; range 16 to 64 years) (SLEn+ group) and 30 patients without renal involvement (30 females; mean age 39.1 \pm 8.2 years; range 22 to 55 years) (SLEn- group) were included in this retrospective study. All patients' clinical characteristics and laboratory data which include erythrocyte sedimentation rate, C-reactive protein, white blood counts, neutrophil counts, lymphocyte counts, platelet counts, and MPV levels were obtained from medical records. The laboratory data at the highest proteinuria periods of the patients with renal involvement were recorded.

Results: Mean MPV (SLEn+ =9.1 \pm 2.2 , SLEn- $=7.9 \pm 1.2, p=0.001)$ and NLR (SLEn+ $=5.9 \pm 5.9$, SLEn- $=2.6 \pm 2.5, p<0.001)$ values were significantly higher in lupus nephritis group. Besides, a positive correlation between NLR and C-reactive protein was found in lupus nephritis group $(r=1.97, p=0.045)$. Based on receiver operating characteristic curve with area under the curve of 0.76 , cutoff NLR value of 1.93 had $83 \%$ sensitivity and $54 \%$ specificity [95\% confidence interval, $0.66-0.85$ ] in differentiating SLE patients with or without nephritis.

Conclusion: Neutrophil to lymphocyte ratio and MPV may be discriminative for lupus nephritis. Also, NLR may be a predictor of lupus nephritis. Both MPV and NLR values may be affected by a great number of factors; therefore, further prospective studies are needed to evaluate the use of these parameters in SLE.

Keywords: Mean platelet volume; nephritis; neutrophil to lymphocyte ratio; systemic lupus erythematosus.
\end{abstract}

Systemic lupus erythematosus (SLE) is a systemic autoimmune disease of unknown etiology with different clinical and laboratory characteristics. ${ }^{1}$ SLE goes on with organ involvements by remission and relapses. ${ }^{2}$ Lupus nephritis (LN) is an immune complex glomerulonephritis which develops as a complication of SLE. ${ }^{3}$ SLE nephritis appears in approximately $50 \%$ of the SLE patients, which increases the risk of renal failure, cardiovascular diseases, and death. ${ }^{4}$ Attentive follow-up is critical particularly for SLE patients with renal involvement. SLE disease activity is assessed via composite indexes such as Systemic Lupus Erythematosus Disease Activity Index, Systemic Lupus Activity Measure, European Consensus Lupus Activity Measurements, and British Isles Lupus Assessment Group. ${ }^{5}$ However, routine clinical use of these indices are limited due to their impracticality. Contradictory research results have been reported about the effectiveness of use of anti-double stranded deoxyribonucleic acid and serum complementary levels which are common in SLE and SLE nephritis disease activity. ${ }^{6,7}$ There is no reliable laboratory test as of yet which can 
recognize and indicate SLE's flares, ${ }^{5}$ thus research is ongoing in this area.

Studies on mean platelet volume (MPV) and neutrophil to lymphocyte ratio (NLR) have been part of the relevant literature for the past decade. There are numerous reports on the inflammatory relationship between NLR and malignancy, ischemic injury, cardiovascular disease, and infection. ${ }^{8-10}$ Hypertension, diabetes, coronary artery disease are examples of diseases for which the relationships with MPV have been examined. ${ }^{11-13}$ MPV has been evaluated in chronic inflammatory diseases such as rheumatoid arthritis, ankylosing spondylitis, and Behçet's disease. ${ }^{14-16}$ Due to their inflammatory roles, MPV and NLR may be used as inflammatory markers in LN, which is known as a systemic, autoimmune complication of SLE. Yavuz and Ece ${ }^{17}$ have suggested MPV as a disease activation indicator for juvenile SLE nephritis patients. Furthermore, Çankaya and Bilen ${ }^{18}$ have shown that MPV can be an activation indicator in patients with SLE renal involvement. In a study by Qin et al., ${ }^{19}$ NLR was shown to be related with SLE disease activity. ${ }^{19}$ Last but not least, Li et al. ${ }^{20}$ have reported NLR as a marker for SLE nephritis. Therefore, in this study, we aimed to evaluate the role of NLR and MPV as activation and inflammatory markers in SLE patients with nephritis.

\section{PATIENTS AND METHODS}

The data of this study were obtained retrospectively from the files of patients diagnosed with SLE between January 2000 and June 2015 in our clinic based on American College of Rheumatology classification criteria for SLE. ${ }^{21}$ Ethical approval for the study was obtained from the local ethics committee. A written informed consent was obtained from each patient. The study was conducted in accordance with the principles of the Declaration of Helsinki. The study included a total of 108 SLE patients (8 males, 100 females; mean age $35.3 \pm 10.2$ years; range 16 to 64 years) including 78 patients with renal involvement (8 males, 70 females; mean age $33.9 \pm 10.6$ years; range 16 to 64 years) (SLEn+ group) and 30 patients without renal involvement (30 females; mean age $39.1 \pm 8.2$ years; range 22 to 55 years) (SLEn- group). LN was defined as clinical and laboratory manifestations that meet American College of Rheumatology criteria. Erythrocyte sedimentation rate, C-reactive protein (CRP), white blood counts, neutrophil counts, lymphocyte counts, platelet counts, and MPV levels were recorded from the files of patients. The laboratory data at the highest proteinuria periods of the patients with renal involvement were recorded. Renal biopsies were assessed according to World Health Organization classification.

\section{Statistical analysis}

Statistical analysis was carried out via IBM SPSS version 20.0 for Windows (IBM Corporation, Armonk, NY, USA). Differences between the two groups were assessed via t-test or Mann-Whitney $\mathrm{U}$ test, as appropriate. Chi-square test was used to compare proportions in different groups. Correlations among variables were assessed using the Pearson and/or Spearman rank coefficient. We evaluated the area under the curve using receiver operating characteristic curve in order to evaluate the discrimination value of NLR and MPV for SLE patients with or without nephritis. A value of $p<0.05$ was considered to be statistically significant for all tests.

\section{RESULTS}

Erythrocyte sedimentation rate and CRP were similar between the groups. Mean platelet counts were also similar in both groups; however, mean leukocyte and neutrophil counts were significantly lower in SLEn- group while mean lymphocyte counts were significantly lower in SLEn+ group (Table 1). We observed that renal biopsies have been made on 52 of 78 patients. Pathological staging could not be carried out since proper samples could not be acquired from 14 of these 52 patients. LN was confirmed via biopsy on 38 of the patients; of these patients, 23 were proliferative LN (60.52\%), 11 were stage 5 LN (28.94\%), three were stage $6 \mathrm{LN}$ (7.89\%), and one was stage 2 LN (2.63\%). Mean MPV and NLR values were significantly higher in SLEn+ group $(p=0.001$ and $p<0.001$, respectively). In addition, we found a positive correlation between NLR and CRP in lupus nephritis group ( $p=0.045, r=1.97)$. Based on receiver operating characteristic curve with area under the curve of 0.76, cutoff NLR value of 1.93 had $83 \%$ sensitivity and 54\% 


\begin{tabular}{|c|c|c|c|}
\hline \multirow[t]{2}{*}{ Parameter } & SLEn+ $(n=78)$ & SLEn- $(\mathrm{n}=30)$ & \multirow[b]{2}{*}{$p$} \\
\hline & Mean \pm SD & Mean \pm SD & \\
\hline Erythrocyte sedimentation rate (mm/hour) & $29.3 \pm 21.8$ & $21.9 \pm 15.2$ & 0.052 \\
\hline C-reactive protein $(\mathrm{mg} / \mathrm{dL})$ & $1.4 \pm 2.6$ & $0.7 \pm 1.1$ & 0.06 \\
\hline White blood counts $\left(\times 10^{3} / \mathrm{mm}^{3}\right)$ & $7.6 \pm 3.7$ & $6.2 \pm 1.9$ & 0.014 \\
\hline Neutrophyl $\left(\times 10^{3} / \mathrm{mm}^{3}\right)$ & $5.6 \pm 3.4$ & $3.8 \pm 1.9$ & 0.001 \\
\hline Lymphocyte $\left(\times 10^{3} / \mathrm{mm}^{3}\right)$ & $1.4 \pm 0.8$ & $1.8 \pm 0.6$ & 0.003 \\
\hline Platelet $\left(\times 10^{3} / \mathrm{mm}^{3}\right)$ & $245.8 \pm 104.6$ & $275.2 \pm 97.8$ & 0.175 \\
\hline Mean platelet volume (fL) & $9.1 \pm 2.2$ & $7.9 \pm 1.2$ & 0.001 \\
\hline Neutrophil lymphocyte ratio & $5.9 \pm 5.9$ & $2.6 \pm 2.5$ & $<0.001$ \\
\hline Complement 3 (mg/dL) & $75.9 \pm 33.9$ & - & \\
\hline Complement 4 (mg/dL) & $13.5 \pm 8.9$ & - & \\
\hline Proteinuria (mg/day) & $4735.0 \pm 4916.3$ & - & \\
\hline
\end{tabular}

specificity [95\% confidence interval, 0.66-0.85] in differentiating SLE patients with or without nephritis (Figure 1).

\section{DISCUSSION}

This retrospective study demonstrated that MPV and NLR increased significantly in active SLE nephritis compared to SLE without renal involvement. MPV and NLR may be useful in SLE nephritis to detect flares and achieve remission earlier as a result of decreased mortality and morbidity.

Mean platelet volume and NLR were investigated in various rheumatic diseases. It has been detected that MPV and NLR levels were higher in Behçet's disease. ${ }^{22,23}$ Moreover, NLR and MPV had higher levels at the attack periods in familial Mediterranean fever patients. ${ }^{24,25}$ High levels of MPV and NLR have been found as a predictor for gastrointestinal bleeding in the Henoch-Schonlein purpura. ${ }^{26,27}$ Decreased MPV and NLR have been shown with the treatment of rheumatoid arthritis and ankylosing spondylitis. ${ }^{28,29}$ Increased MPV in systemic sclerosis patients was found to be a predictive marker for macrovascular and microvascular disease involvement of systemic sclerosis. ${ }^{30}$ Furthermore, NLR has been shown to be a useful index to estimate primary Sjogren's syndrome disease activity. ${ }^{31}$

Systemic lupus erythematosus is a chronic autoimmune inflammatory disease which might exhibit variable clinical processes with relapses. Complement and anti-double stranded deoxyribonucleic acid levels are used for SLE and SLE nephritis as activity markers. ${ }^{5}$ Elevated erythrocyte sedimentation rate may indicate disease activation. ${ }^{32}$ NLR and MPV are cost effective and easily obtained inflammatory indicators from complete blood count tests. It is

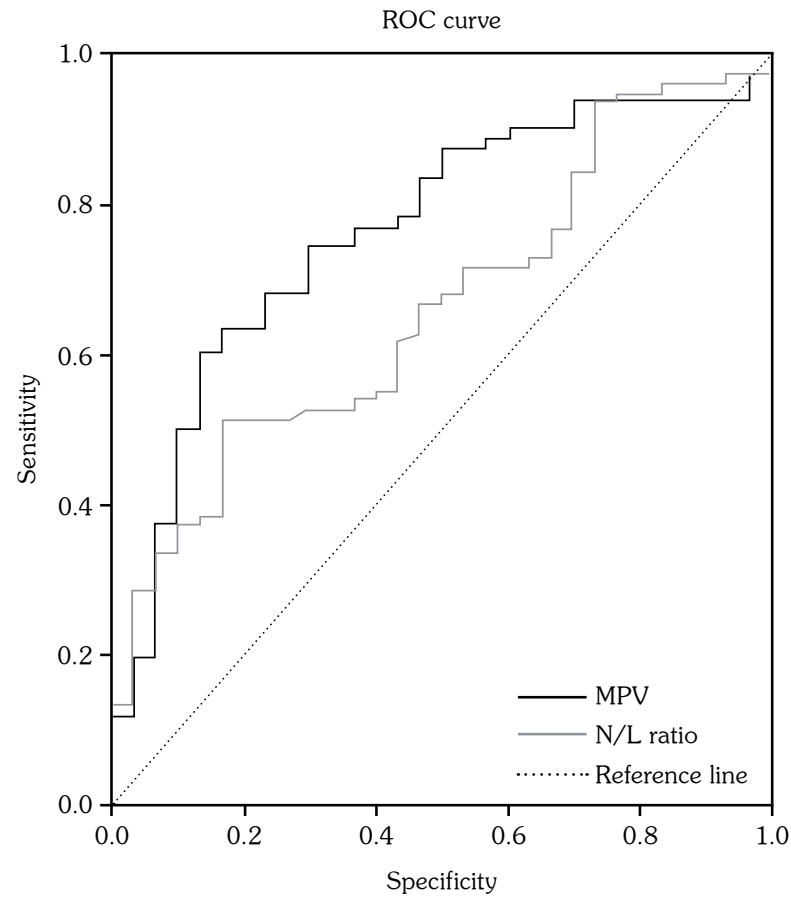

Figure 1. Receiver operating characteristic curve analysis of neutrophil to lymphocyte ratio to predict lupus nephritis showed that area under the curve was 0.76 . Cutoff value using ROC curve was 1.93 (sensitivity, 0.83; specificity, 0.54; 95\% confidence interval, 0.66-0.85; $\mathrm{p}<0.001$ ). However, area under the curve for mean platelet volume was lower than 0.7. ROC: Receiver operating characteristic; MPV: Mean platelet volume; N/L: Neutrophil to lymphocyte. 
widely known that an opposite correlation exists between MPV and platelet count. ${ }^{33} \mathrm{MPV}$ is related with inflammatory and thrombotic courses. ${ }^{33}$ It was put forth that NLR had augmentation in several inflammatory conditions. ${ }^{34} \mathrm{MPV}$ and NLR might also be disease activity indicators for SLE nephritis. Li et al. ${ }^{20}$ suggested that NLR can predict LN with a cutoff value of 4.4 for NLR (sensitivity 0.64 , specificity 0.91 ). According to Oehadian et al. ${ }^{35}$ cutoff NLR value of $\geq 1.93$ had sensitivity of 0.70 and specificity of 0.67 in differentiating SLE patients and normal subjects. Çankaya and Bilen ${ }^{18}$ determined that MPV increases statistically significantly during the active period of SLE patients with renal involvement. Moreover, Yavuz and $\mathrm{Ece}^{17}$ reported that MPV was superior than erythrocyte sedimentation rate, $\mathrm{CRP}$ and $\mathrm{C} 3$ to predict disease flares in juvenile SLE. Higher levels of NLR have been achieved in SLE patients with nephritis compared to those without nephritis and at a cutoff NLR value of 2.66 has been shown in Qin's ${ }^{19}$ report for prediction of SLE nephritis. We demonstrated statistically significantly increased levels of MPV and NLR in active SLE nephritis in our study. We found NLR to have a positive correlation with CRP. We also showed that, based on receiver operating characteristic curve with area under the curve of 0.76 , cutoff NLR value of 1.93 had $83 \%$ sensitivity and 54\% specificity in differentiating SLE patients with or without nephritis.

Inter-group ages in our study were different. However, a study with 8,082 individuals from general population has shown that MPV does not correlate with age. ${ }^{36}$ In our study, NLR levels were higher in the nephritic group which was also younger than the non-nephritic group. On the other hand, $\mathrm{Li}$ et al. determined a positive correlation between NLR and age for 3,262 individuals from a healthy population. ${ }^{37}$ Thus, we think that the difference in inter-group ages has not affected our study results.

The limitations of this study are that it is a single center study with a retrospective design and activation index of SLE has not been used.

In conclusion, both NLR and MPV were increased in SLE patients with nephritis compared to SLE patients without nephritis. NLR may be a predictor of LN. Both MPV and NLR values may be affected by a great number of factors; therefore, further prospective studies are needed to evaluate the use of these parameters in SLE.

\section{Declaration of conflicting interests}

The authors declared no conflicts of interest with respect to the authorship and/or publication of this article.

\section{Funding}

The authors received no financial support for the research and/or authorship of this article.

\section{REFERENCES}

1. Domsic RT, Goldman RR, Manzi S. Systemic lupus eritematozus epidemyology and classification. In: Hochberg MC, Silman AC, editors. 4th ed. Rheumatology: Mosby Elsevier; 2008. p. 1211-5.

2. Ruperto N, Hanrahan LM, Alarcón GS, Belmont HM, Brey RL, Brunetta P, et al. International consensus for a definition of disease flare in lupus. Lupus 2011;20:453-62.

3. Sterner RM, Hartono SP, Grande JP. The Pathogenesis of Lupus Nephritis. J Clin Cell Immunol 2014;5. pii: 205.

4. Bertsias GK, Tektonidou M, Amoura Z, Aringer $\mathrm{M}$, Bajema I, Berden $\mathrm{JH}$, et al. Joint European League Against Rheumatism and European Renal Association-European Dialysis and Transplant Association (EULAR/ERA-EDTA) recommendations for the management of adult and paediatric lupus nephritis. Ann Rheum Dis 2012;71:1771-82.

5. Liu CC, Ahearn JM. The search for lupus biomarkers. Best Pract Res Clin Rheumatol 2009;23:507-23.

6. Liu CC, Ahearn JM, Manzi S. Complement as a source of biomarkers in systemic lupus erythematosus: past, present, and future. Curr Rheumatol Rep 2004;6:85-8.

7. Isenberg DA, Manson JJ, Ehrenstein MR, Rahman A. Fifty years of anti-ds DNA antibodies: are we approaching journey's end? Rheumatology (Oxford) 2007;46:1052-6.

8. Hung HY, Chen JS, Yeh CY, Changchien CR, Tang R, Hsieh PS, et al. Effect of preoperative neutrophillymphocyte ratio on the surgical outcomes of stage II colon cancer patients who do not receive adjuvant chemotherapy. Int J Colorectal Dis 2011;26:1059-65.

9. Celik T, Bugan B. White blood cell count and stable coronary artery disease: the role of neutrophil to lymphocyte ratio. Cardiol J 2011;18:720.

10. de Jager $\mathrm{CP}$, van Wijk PT, Mathoera RB, de Jongh-Leuvenink $J$, van der Poll $T$, Wever PC. Lymphocytopenia and neutrophil-lymphocyte count ratio predict bacteremia better than conventional infection markers in an emergency care unit. Crit Care 2010;14:R192. 
11. Inanc T, Kaya MG, Yarlioglues M, Ardic I, Ozdogru I, Dogan $\mathrm{A}$, et al. The mean platelet volume in patients with non-dipper hypertension compared to dippers and normotensives. Blood Press 2010;19:81-5.

12. Zuberi BF, Akhtar N, Afsar S. Comparison of mean platelet volume in patients with diabetes mellitus, impaired fasting glucose and non-diabetic subjects. Singapore Med J 2008;49:114-6.

13. Pizzulli L, Yang A, Martin JF, Lüderitz B. Changes in platelet size and count in unstable angina compared to stable angina or non-cardiac chest pain. Eur Heart $\mathrm{J}$ 1998;19:80-4.

14. Gasparyan AY, Stavropoulos-Kalinoglou A, Mikhailidis DP, Douglas KM, Kitas GD. Platelet function in rheumatoid arthritis: arthritic and cardiovascular implications. Rheumatol Int 2011;31:153-64.

15. Yazici S, Yazici M, Erer B, Erer B, Calik Y, Bulur S, et al. The platelet functions in patients with ankylosing spondylitis: anti-TNF-alpha therapy decreases the mean platelet volume and platelet mass. Platelets 2010;21:126-31.

16. Acikgoz N, Karincaoglu Y, Ermis N, Yagmur J, Atas $\mathrm{H}$, Kurtoglu $\mathrm{E}$, et al. Increased mean platelet volume in Behçet's disease with thrombotic tendency. Tohoku J Exp Med 2010;221:119-23.

17. Yavuz S, Ece A. Mean platelet volume as an indicator of disease activity in juvenile SLE. Clin Rheumatol 2014;33:637-41.

18. Çankaya E, Bilen Y. Mean platelet volume significantly decrease at remission period of SLE patients with renal involvement. Nephrol Dial Transplant 2015;30(Suppl 3):439.

19. Qin B, Ma N, Tang Q, Wei T, Yang M, Fu H, et al. Neutrophil to lymphocyte ratio (NLR) and platelet to lymphocyte ratio (PLR) were useful markers in assessment of inflammatory response and disease activity in SLE patients. Mod Rheumatol 2016;26:372-6.

20. Li L, Xia Y, Chen C, Cheng P, Peng C. Neutrophillymphocyte ratio in systemic lupus erythematosus disease: a retrospective study. Int $\mathrm{J}$ Clin Exp Med 2015;8:11026-31.

21. Hochberg MC. Updating the American College of Rheumatology revised criteria for the classification of systemic lupus erythematosus. Arthritis Rheum 1997;40:1725.

22. Uzkeser H, Haliloglu S, Cayir Y, Bilen N, Karaaslan Y, Kosar A, et al. Is mean platelet volume a new activity criteria in Behçet's disease? Blood Coagul Fibrinolysis 2015;26:836-9.

23. Rifaioglu EN, Bülbül Şen B, Ekiz Ö, Cigdem Dogramaci A. Neutrophil to lymphocyte ratio in Behçet's disease as a marker of disease activity. Acta Dermatovenerol Alp Pannonica Adriat 2014;23:65-7.

24. Celikbilek M, Dogan S, Akyol L, Borekci E, Zararsiz G, Kozan M, et al. Neutrophil-lymphocyte ratio in patients with familial Mediterranean fever. J Clin Lab
Anal 2015;29:80-3.

25. Arıca S, Ozer C, Arıca V, Karakuş A, Celik T, Güneşaçar R. Evaluation of the mean platelet volume in children with familial Mediterranean fever. Rheumatol Int 2012;32:3559-63.

26. Makay B, Gücenmez ÖA, Duman M, Ünsal E. The relationship of neutrophil-to-lymphocyte ratio with gastrointestinal bleeding in Henoch-Schonlein purpura. Rheumatol Int 2014;34:1323-7.

27. Makay B, Türkyilmaz Z, Duman M, Unsal E. Mean platelet volume in Henoch-Schönlein purpura: relationship to gastrointestinal bleeding. Clin Rheumatol 2009;28:1225-8.

28. Coşkun BN, Öksüz MF, Ermurat S, Tufan AN, Oruçoğlu N, Doğan A, et al. Neutrophil lymphocyte ratio can be a valuable marker in defining disease activity in patients who have started antitumor necrosis factor (TNF) drugs for ankylosing spondylitis. Eur J Rheumatol 2014;1:101-5.

29. Yazici S, Yazici M, Erer B, Erer B, Calik Y, Bulur S, et al. The platelet functions in patients with ankylosing spondylitis: anti-TNF-alpha therapy decreases the mean platelet volume and platelet mass. Platelets 2010;21:126-31.

30. Soydinc S, Turkbeyler IH, Pehlivan Y, Soylu G, Goktepe MF, Bilici M, et al. Mean platelet volume seems to be a valuable marker in patients with systemic sclerosis. Inflammation 2014;37:100-6.

31. Hu ZD, Sun Y, Guo J, Huang YL, Qin BD, Gao Q, et al. Red blood cell distribution width and neutrophil/ lymphocyte ratio are positively correlated with disease activity in primary Sjögren's syndrome. Clin Biochem 2014;47:287-90.

32. Morrow WJ, Isenberg DA, Todd-Pokropek A, Parry HF, Snaith ML. Useful laboratory measurements in the management of systemic lupus erythematosus. Q J Med 1982;51:125-38.

33. Gasparyan AY, Ayvazyan L, Mikhailidis DP, Kitas GD. Mean platelet volume: a link between thrombosis and inflammation? Curr Pharm Des 2011;17:47-58.

34. Zahorec R. Ratio of neutrophil to lymphocyte counts--rapid and simple parameter of systemic inflammation and stress in critically ill. Bratisl Lek Listy 2001;102:5-14.

35. Oehadian A, Suryadinata H, Dewi S, Pramudyo R, Alisjahbana $\mathrm{B}$. The role of neutrophyl lymphocyte count ratio as an inflammatory marker in systemic lupus erythematosus. Acta Med Indones 2013;45:170-4.

36. Hoffmann JJ, van den Broek NM, Curvers J. Reference intervals of reticulated platelets and other platelet parameters and their associations. Arch Pathol Lab Med 2013;137:1635-40.

37. Li J, Chen Q, Luo X, Hong J, Pan K, Lin X, et al. Neutrophil-to-Lymphocyte Ratio Positively Correlates to Age in Healthy Population. J Clin Lab Anal 2015;29:437-43. 